\title{
BMJ Open Mental health of South Asian youth in Peel Region, Toronto, Canada: a qualitative study of determinants, coping strategies and service access
}

\author{
Farah Islam, ${ }^{1}$ Amanpreet Multani, ${ }^{2}$ Michaela Hynie, ${ }^{3}$ Yogendra Shakya, ${ }^{4}$ \\ Kwame McKenzie ${ }^{1}$
}

To cite: Islam F, Multani A, Hynie M, et al. Mental health of South Asian youth in Peel Region, Toronto, Canada: a qualitative study of determinants, coping strategies and service access. BMJ Open 2017;7:e018265. doi:10.1136/ bmjopen-2017-018265

- Prepublication history for this paper is available online. To view please visit the journal (http://dx.doi.org/10.1136/ bmjopen-2017-018265)

Received 19 June 2017 Revised 3 October 2017 Accepted 9 0ctober 2017

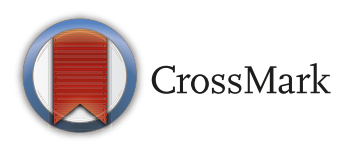

${ }^{1}$ Social Aetiology of Mental IIIness Training Program, Health Systems and Health Equity Research Group, Centre for Addiction and Mental Health, University of Toronto, Toronto, Ontario, Canada

${ }^{2}$ Psychology Program, York University, Toronto, Ontario, Canada

${ }^{3}$ Department of Psychology, York Institute for Health Research, York University, Toronto, Ontario, Canada

${ }^{4}$ Access Alliance Multicultural Health and Community Services, Dalla Lana School of Public Health, University of Toronto, Toronto, Ontario, Canada

Correspondence to

Dr Farah Islam;

islam.farah@gmail.com

\section{ABSTRACT}

Objectives This qualitative study set out to understand the mental health challenges and service access barriers experienced by South Asian youth populations in the Peel Region of Toronto, Canada.

Setting In-depth semistructured interviews were carried out with South Asian youth living in Peel Region (Mississauga, Brampton and Caledon), a suburb of Toronto, Canada, home to over $50 \%$ of Ontario's South Asian population.

Participants South Asian youth $(n=10)$ engaged in thoughtful, candid dialogue about their mental health and service access barriers.

Primary and secondary outcome measures Qualitative interview themes related to mental health stressors and mental health service access barriers experienced by youth living in Peel Region were assessed using thematic analysis.

Results South Asian youth face many mental health stressors, from intergenerational and cultural conflict, academic pressure, relationship stress, financial stress and family difficulties. These stressors can contribute to mental health challenges, such as depression and anxiety and drug use, with marijuana, alcohol and cigarettes cited as the most popular substances. South Asian youth were only able to identify about a third (36\%) of the mental health resources presented to them and did not feel well informed about mental health resources available in their neighbourhood. Conclusions They offered recommendations for improved youth support directed at parents, education system, South Asian community and mental health system. Institutions and bodies at all levels of the society have a role to play in ensuring the mental health of South Asian youth.

\section{INTRODUCTION}

Canada is home to an ever-increasing population of migrants from all over the world. In recent years, Canada has witnessed large numbers of immigrants from Asia and Africa. South Asian, Chinese and black populations accounted for $61.3 \%$ of the racialised population in Canada in 2011, with South Asians making up the largest segment at $25 \% .^{1}$ In Ontario, large populations of South Asian immigrants have made parts of the Greater
Strengths and limitations of this study

- In-depth semistructured interviews with youth allowed for rich qualitative data collection.

- This is one of the first studies to focus on the mental health and service access issues experienced by South Asian youth living in Peel Region, home to over $50 \%$ of Ontario, Canada's South Asian population.

- The stigmatised nature of mental illness made it difficult to recruit youth, and the sample was biased towards women, likely because of the different socialisation of men and women in regard to sharing emotions and personal life histories.

- The difficulty with recruitment, the heterogeneity of the participants and the lack of follow-up interviews did not allow for thematic saturation to be achieved.

Toronto Area (GTA) their home. Peel Region, part of the GTA just west of Ontario's capital, consists of the cities of Brampton, Mississauga and the town of Caledon. Peel Region is home to a large population of immigrants from South Asian countries such as India, Pakistan, Bangladesh, Sri Lanka and Nepal, and these numbers are increasing. Over half of all youth in Peel Region belong to racialised communities and South Asian populations. ${ }^{2}$

Youth are at critical stage of life for mental health and substance use intervention. ${ }^{3}$ According to the National Institute of Mental Health, ${ }^{4} 50 \%$ of cases of lifetime mental illness and addiction issues begin before the age of 14 , and $75 \%$ of cases begin before the age of 24. Substance abuse and addiction usually present in early adulthood. ${ }^{4}$ Mental healthcare treatment and intervention that begin at an early age greatly increases a young person's chances of recovery. ${ }^{5}$ As South Asian communities in Peel Region continue to grow, there is a need to address specific issues affecting the mental health and well-being of these communities, particularly 
for youth. Various acculturative stressors can accompany growing up in Canada as a new immigrant or the child of immigrants. ${ }^{6}$ South Asian youth face the task of balancing family expectations, cultural standards and religious demands, all of which can cause internal and external conflict. Anisef and Kilbride ${ }^{7}$ found that immigrant and newcomer youth face many stressors, including identity development and language barriers. In addition, many youth face challenging intergenerational conflict, competing between their own values and the values of the elders of the community. It is important to also note the heterogeneity of different South Asian youth populations. Muslim immigrant youth may be at risk for maladaptation in the host country because of discrimination and difficulties in cultural transition. ${ }^{8}$ On the other hand, stressors such as peer relations, lack of attention from parents and parental pressure to succeed have been identified for Punjabi Sikh youth. ${ }^{9}$ Each subpopulation of youth faces unique challenges to their mental health.

Research with South Asian adults in Canada has found lower prevalence rates of mental health service use. ${ }^{10}$ Gadalla $^{11}$ found that almost one-third of South Asians diagnosed with major depressive episode cited no access to available care. South Asian populations face many barriers, including language barriers, lack of culturally safe care through providers and agencies that cater to specific religious and cultural needs, lack of integration between services and agencies, transportation issues, as well as the lack of awareness and presence of stigma regarding mental health in the community. However, there is little to no research available on the mental health service access barriers specifically affecting South Asian youth populations. In line with the Mental Health Strategy of Canada's ${ }^{12}$ goal to reduce disparities in risk factors and access to mental health services and to strengthen the ability to meet the needs of diverse communities, further research is needed to understand the issues facing the growing South Asian youth population. Thus, this present study sought to obtain a deeper understanding of how South Asian youth populations in Peel Region define mental health, their mental health concerns, their level of knowledge of available mental health resources and the major barriers they face when seeking care in order to inform the development of effective mental health services and resources in Peel Region that are responsive to the needs of South Asian youth populations.

\section{METHODS}

\section{Research design and research questions}

A qualitative study was designed as part of a larger multimethod study to answer the following research questions:

1. How do South Asian youth define 'mental health' and 'recovery'?

2. What are the major mental health concerns of South Asian youth?

3. What are the barriers to mental health service access for South Asian youth living in Peel Region?
4. Which mental health services are South Asian youth familiar with?

5. What recommendations do South Asian youth have for improving mental health service access in Peel Region?

\section{Theoretical frameworks}

A social determinants of health (SDOH) and intersectionality lens were applied to this research project. Mikkonen and Raphael ${ }^{13}$ stress the importance of considering social factors impacting on health and healthcare access, such as socioeconomic status, education, social exclusion and ethnicity. Khanlou ${ }^{14}$ asserts the importance of contextualising the individual within 'intersectionalities of influence'. Mental health and attitudes towards seeking care are complex phenomena, and this study cuts across many critical intersections such as migration, acculturation pressures, religion and gender. Care was taken to develop a complete picture of each individual's context to understand the impact of cross-cutting and unique contextual factors on attitudes towards seeking mental healthcare rather than oversimplify and further marginalise. Important contextual variables such as gender, social support and socioeconomic status were included in this study to capture the complexities of participants' everyday lived experiences that shape mental health status, perspectives about mental health, and coping and service access strategies.

\section{Sampling}

Purposive homogeneous sampling or purposeful/ non-random sampling from a single segment of the population ${ }^{15}$ was carried out. South Asian youth (13-24 years old) living in Peel Region were recruited from March to July 2015. The recruitment flyer was posted in public areas of congregation (community centres, public libraries, universities and others) and through social media. Youth workers such as social workers, school counsellors, religious leaders, psychiatrists, mental health therapists and others were approached as well to encourage their clients to participate. Youth proved to be much more difficult to recurit than anticipated likely because of the stigmatised nature of mental illness. The majority of youth were recruited through social workers from various organisations. Full written consent was obtained from the youth participants and parental consent for those below the age of 18. Youth interviews began in May 2015. A total of 10 South Asian youth participated in one-on-one in-depth interviews. Interviews were conducted at locations convenient for the participant (eg, school, public library and others).

\section{Interviews}

A semistructured in-depth interview/focus group guide was developed to investigate the study's research questions. The following are some examples of questions: 'Can you name some sources of stress in your life?' and 'What are some recurring conflicts you have with your 
parents/guardians?' The interview guide was developed based on interviews with youth workers in Peel Region regarding the mental health challenges and service access barriers South Asian youth face. The interview questions were informed with a $\mathrm{SDOH}^{13}$ and intersectionality lens. ${ }^{14}$ Interviews were offered with the following choice of language options: English, Punjabi, Urdu, Hindi and Bengali. All interviews were conducted in English except for one in Bengali. Youth participants were given a $\$ 15$ gift card on agreeing to partake in the study. The interviews lasted on average for about an hour and a half and were audio-recorded using the 'Easy Sound Recorder' app downloaded on a Windows Surface tablet. The mp3 files were translated and transcribed into English for analysis. The interview questions were not translated/ back-translated. Rather, the interviewer translated the one Bengali interview from the English guide as she conducted the interview. The interviewers were bilingual. The translation of the interview was done by the bilingual interviewer.

\section{Rigour}

Several strategies were employed to ensure rigour in this study. ${ }^{16-18}$ Former and current residents of Peel, youth living at home and those who were not, youth currently in school as well as those who had dropped out, users and non-users of the mental health system, and youth who had professionals recommend they seek mental health services but chose not to follow through were interviewed to ensure a wide range of youth perspectives could be captured. The recruitment poster had Punjabi, Hindi and Urdu writing to attract non-English-speaking South Asian youth. Interviews were offered in the major South Asian languages in Peel Region (Punjabi, Urdu, Hindi and Bengali), and the interview team travelled to any location that was convenient for the participant. A self-reflexive journal and field notes were kept for reference and to contextualise the analysis of the data. Researcher positionality was noted and reflected on during the interview and analysis as the researcher could be viewed as both an insider (South Asian immigrant to Canada, Peel Region resident) and outsider (adult, academic).

The first author analysed the transcripts. The transcripts and coding were reviewed by the three senior mentors and authors of this paper. Peer auditing took place, where the analysis of the transcripts was presented to some of the youth participants. The youth felt the analysis was successful in capturing their thoughts and concerns.

Lastly, member checking took place after the study, where findings were presented to youth (13-24 years old) from both South Asian and non-South Asian backgrounds living in GTA in multiple community forums. All youth expressed that the findings presented resonated with their life experiences.

\section{Data analysis}

The interview transcript text was analysed using Braun and Clarke's ${ }^{19}$ guidelines on thematic analysis. Thematic analysis was used to identify, analyse and report the patterns within the interview transcripts and describe the findings in rich detail. The basic elements of interest in the transcribed interviews were preliminarily coded. This coding was largely conceptually/theory-driven (as opposed to data-driven) following the research questions. A constant comparative technique and iterative refinement process were used throughout. Qualitative analysis was done manually, and codes were organised into subthemes and overarching themes. Themes or patterns related to the five research questions outlined above were searched for in the interview transcripts. A thematic map was finalised, and detailed analyses were written for each theme.

\section{RESULTS}

\section{Youth sample profile}

The sample of youth participants ranged in age from 15 to 23 years old (mean: 20; SD: 2.44). Two young men and eight women were interviewed, for a total of 10 participants $(n=10)$. Seven were current/former residents of Mississauga, while five participants were current/former residents of Brampton (two participants had lived in both cities). There were three Canadian-born and seven immigrant participants. On average, the immigrant youth had lived in Canada for over 12 years (SD: 5.56). A few had experienced multiple migrations. The youth represented the following countries in terms of South Asian ancestry: India, Pakistan, Bangladesh, Trinidad and Guyana, and represented the three major South Asian religions of Islam, Hinduism and Sikhism. Seven youth reported accessing mental health services. This high number is likely explained due to the majority of the referrals by social workers. Three youth also mentioned having a family member with mental illness. Youth reported mental health consultation with their family doctor, general practitioner, psychiatrist, psychologist, counsellor and social worker. Sample sizes for the majority of characteristics have been omitted to ensure confidentiality of youth participants.

\section{Major themes \\ Definitions of 'Mental Health' and 'Recovery'}

Participants had varying definitions of mental health that encompassed psychological, cognitive, social, environmental and behavioural aspects of mental health. Positive mental health was often described as being well-rounded and having balance in one's life. "It's like your ability to process information, your emotions, and like how you respond to situations...Positive mental health?...involved in extra curriculars...go out with friends, volunteer, so just involved in the community" (Youth \#6). About half the youth spoke of mental health negatively and solely in terms of illness rather than health. Mental health was described as "mentally problems" (Youth \#8) and "physical sickness" (Youth \#3). 
The youth felt that recovery needed to be self-motivated. "...you have to tell yourself you want to recover. You can't just take other people's word for it" (Youth \#9). Youth also felt that social support was important for the process. However, many felt that support, especially from family, was lacking because of stigma. The resulting social isolation can further undermine recovery.

Often the recovery for some, mental health issues, they often come with the support of your family. They are usually your number one resource, especially for South Asian people, because you live with your family. Usually, you can't openly talk about your recovery with your parents because then they will know that oh, you're going through a mental health crisis? Why didn't you tell us first? Again the blame goes back on you. You can't go to the mosque. You can't go to the imam [Muslim religious leader]. You can't tell them hey, I am going through this issue. You can't tell them why. You can't tell anyone. The recovery too, is a very lonely process...I feel if you don't have support in the recovery process it's not going to work. Cuz recovery, the whole point is so that you can be well adjusted again. It's just not going to happen by yourself. So that's why like there is no support in that sense. (Youth \#7)

\section{Mental health concerns}

Acculturation stress and intergenerational conflict

Conflicts with parents were the major mental health stressor raised by South Asian youth. Overall, the underlying root for these conflicts was related to migration and resettlement and how this creates a dynamic where two very different cultures (Western/Canadian and South Asian) have to coexist under the same roof.

...our parents came here because they wanted to give us a good education. A lot of parents aren't understanding that when you come here, you also have to adapt to the environment. You don't just move for the money. You have to adapt to everything else that comes along with it. (Youth \#3)

The youth spoke about having to be "cross-culture kid[s]" with a "dual identity" (Youth \#1). The parents and youth found themselves in a constant struggle to find balance and mutual understanding. All too often, because of the power differential, the youth felt they had to be the yielding party because their parents refused to adapt. "They don't have the tools. Nobody tells you how to transition when you move to a country with a different culture. And then the kids have to bear the brunt of it...I had to bear the brunt inside me for so many years" (Youth \#1). For some, the rules set were not up for discussion and strict obedience was expected, which left youth feeling resentful. "My mom wants me to do everything from her point of view, her way. Not my way, not anyone else's way, her way" (Youth \#8).

\section{Academic pressure from parents}

One of the major arenas for this intergenerational family tension was in terms of academic pressure to succeed at school and have a good career. Youth also spoke about this pressure extending to expectations of perfection at home. "Like studies, study, study! And to pray, you have to be religious and studious, you can't really go out. It's kind of like you are home-grown. Basically home life. That is basically my tradition. And chores. You have so many chores to do. Lots of responsibility" (Youth \#6). Youth felt that parents rigidly conformed to the South Asian community's expectations and norms of what "success" should look like rather than consider their child's feelings. "This comes down to what career choices South Asian people have, usually lawyer, medicine, engineer, there's not a lot" (Youth \#7). South Asian youth felt they were put under extreme pressure to succeed and felt particularly frustrated that no matter what they did, their parents still constantly compared them with some "model student," where they always failed in comparison.

Everything I did for my parents was to make them happy. But everything they did, their expectations were up here. They compared me to doctors and engineers when I was in grade 4. It was stressful. I guess it is family image... They force us to, it's like 99\% or you don't come home...And then they compare you to other people's kids. They tell you, you know that kid studies 20 hours a day. (Youth \#9)

Comparisons and disappointment also came from the youth, who compared their peers' way of life and couldn't understand the reason for the disparity.

It was strict [at home]. Then you go out to the real world and you ask other kids, other brown kids, I tell them, oh so your parents don't do this. And they say no, they are pretty chill. And then I am just wondering why is that?...I guess that's the culture barrier. (Youth \#9)

\section{Relationship stress}

Marriage, dating and opposite gender interactions were another battleground for parents and youth. Again, youth compared themselves with their peers. "And traditionally in my culture, you don't date. But I want to date. It must be one of those things you see around you a lot, so you want it. It is so popularized. So that is the way you want to do things" (Youth \#1). South Asian parents had expectations that their children would follow traditional norms of finding a spouse for marriage. "My parents would prefer if we met and we go to each other's houses, something like that, with family there" (Youth \#1). Any kind of opposite gender interaction was frowned upon, particularly for female youth. "Even still my mom's mentality is like that. Don't talk to guys. Don't go close to guys. Stay away from guys" (Youth \#8). Youth had a difficult time understanding how they were supposed to get married if opposite gender interaction was not possible and many wanted 
the opportunity to date and explore. The pressure to get married early was reported largely by young women. "And my mom's like, I want you to be married soon! I tell them first of all, I am struggling with mental health issues and second of all, I haven't met anyone. Where is this magical husband going to come from? [laughs] Just kind of these expectations for gender..." (Youth \#1). This lack of guidance on how to navigate opposite gender interactions led some youth to hide relationships from their parents, feel deeply conflicted regarding relationships, and even caused some to fall into depression when the relationships did not work out. "I want to find someone and I just came to the conclusion, I felt really, having a romantic relationship is important to me, and I understand it is also not good" (Youth \#1). "I had a crush on him for 3 years in high school. So as soon as it ended, the summer began, I was miserable. Really really miserable...I tried to get help...my sadness about that was really big" (Youth \#1).

\section{Financial stress}

A number of youth faced financial pressure, particularly for youth growing up in single-parent households and youth who were living on their own. "I think financial reason is the one main reason that my mom [a single parent] had her breakdown because she was worried about us being alone, with no one to care of, I think financial [stress] was also the one reason that sometimes like I get really depressed" (Youth \#3).

I have worked a lot. Since I started living on my own at 17 ...it's like bills after bills after bills. A lot of the time I run out of money so it's just like I just have to like stretch you know, stretch it out. But financial problems, yeah, it's always a problem. (Youth \#9)

\section{Divorce}

In addition, family issues such as parents' divorce were difficult for youth to cope with. Many of the youth took on financial and parental responsibilities to help out at home.

I am very attached to my mom, anything she goes through, I automatically react. So if she's happy, I am happy, if she's not, then I am definitely not. So for me that was a very stressful time...My mom is a single mom and has been for a while, so I have seen her struggle. (Youth \#3)

\section{Mental illness in the family}

Very interestingly, two youth spoke about their mothers having untreated depression, particularly postpartum depression (PPD). The youth felt their mothers not dealing with their mental health issues perpetuated the stigma surrounding mental illness. The lack of role modelling of healthy help-seeking behaviour from their mothers impacted the youth's mental health and made it more difficult for them to seek help for their own mental health issues.
Because I realized later she had postpartum depression and then suffered more depression after I was born and then because it all gets ignored within my family, it all just carries on. And then 10 years later she was just battling general depression. Then my sister was born, then it was postpartum depression. It was just a cycle. (Youth \#10)

\section{Mental health, addictions and drug use}

When it came to mental health and addictions, South Asian youth cited alcohol, tobacco and marijuana as the drugs of choice. Youth cited various reasons for drug and alcohol use, including its use as a coping method to deal with family problems, as a practice youth partake in because they are young and feel immune to its negative consequences, and as a means of rebelling against South Asian tradition.

All the guys were all doing drugs and we, we are maybe not drinking because we're Muslim but some of them even drank. And I think that the reason that this exists because okay so, it's like, I feel a lot of South Asian parents are going through divorce, going through issues at home, which is automatically impacting the children and their way to cope with it is drugs, like violence, or gangs. And I feel it might be not such a big issue in the other cultures because the kids' parents understand that yeah, their issues are also impacting the kids but it also because they are ok with drinking or that stuff, but also they are understanding that if they are going through an issue they will put their kids in counseling sessions or whatnot. (Youth \#3)

Alcohol is strong. Yes. A lot with the Punjabi people... They drink a lot of alcohol including my friends. They kind of do it with the excuse, we're young, why not? I am not sure if they do have an alcohol problem... Ok, my friends that I know like all the brown kids I know...yes, marijuana is number one. (Youth \#9)

I have heard of more like South Asian youth more are drinking now. Because just like non South Asian youth, they think it's a way to forget problems and forget about stuff...South Asian youth sometimes feel like oh this is the only freedom they have sometimes. When they are hanging out, they are kind of like, the social issue, oh yeah, like drink you're Canadian and stuff like that. Even though back home we never drank because of our culture, but here you're rebelling against your culture. (Youth \#7)

\section{Barriers to mental health service access}

Youth reported both systemic-level and family and community-level barriers to mental health service access. At the mental health system level, youth viewed the lack of South Asian mental health professionals in the field, lack of representation of people of South Asian background in mental health promotion, long wait times, prohibitive fees for services not covered by the Ontario 
Health Insurance Plan (OHIP) (eg, psychologist, psychotherapist, counsellors), lack of professionals specialised in youth issues, and lack of variety in terms of models of mental health care. Some youth felt the excessive focus on treating mental health through psychotropic medication and lack of consideration of how religion and other social factors affect mental health made 'Western' or medicalised models of mental health care difficult to accept. On the other hand, some South Asian youth preferred 'Western' models of care and strongly advocated for the use of psychotropic medication. Young adults are savvy in technology and were often very well-informed about the variety of therapies out there (eg, Cognitive Behavioral Therapy (CBT), Mindfulness Therapy, etc) but felt this diversity of services was not available to youth.

...Psychiatrists who deal especially with youth. The thing is that there is not many of them...Also, the lack South Asian mental health professionals... The Western approach to mental health is very very different from the South Asian approach to mental health. One is not better. It's just very different... There is a huge emphasis on meds...Also big difference between Western and South Asian mental health, is that there is more emphasis on religion in South Asian mental health I guess, treatment... In Western health it is very secular and very like you need to do things on your own. (Youth \#7)

One is that I am not targeted for suffering from mental health. I am really not targeted for anything except racism...I feel like some people see a poster and feel like they are not, they don't see themselves in it and feel like they are not included. They will think like oh, only white people suffer from mental health, I am fine, they might think something like that. (Youth \#1)

The youth felt that the education system in Ontario also posed a barrier to mental health service access because of the lack of mental health education incorporated into the curriculum. Youth felt that if they had learnt about the importance of mental health, the warning signs and about available resources from a young age, they would be more open to the idea of seeking care.

They only teach it or recognize physical unhealthy things in your body. Like if you are feeling sick or you feel nauseous or tummy is not feeling well...But there is never anything about if you feel like crying, if you feel very sad, if you feel very angry all the time. (Youth \#10)

Youth were aware of guidance counsellors in schools but also felt that the guidance counsellors were not readily accessible or did not effectively address the mental health needs of students.

In high school too there was no mental health awareness, surprisingly, as far as I knew. You actually had to go to the counselor and book and appointment, which by the way, got cancelled several times. You had to go to the counselor and they tell you resources, but even then they don't properly tell you. They don't educate you. (Youth \#7)

University students felt the restrictions on the number of times a student could have an appointment with the counsellor on campus limited the efficacy of care and ability to develop a relationship with the mental health professional. "You're allowed to see them I think only 5-6 times in the school term... appointments are really really spaced out...So it did help, but only to an extent. The rest of it you need to do by yourself" (Youth \#7).

There is a problem with waiting times. So like you make an appointment and then the next time you want to make an appointment...you'll be lucky if you get it in the next month...therapy with my counselor is sparse...I want something regular. Or and just more, close, more frequent. (Youth \#1)

At the family and community level, mental health stigma arose again and again as a major barrier to seeking mental healthcare.

Sometimes the family feels that if we take him to the hospital, it will help him, but everybody else will know that our child is like this. Family feels like we should not tell anyone that our family has these problems. Because if people know, in the future to get him married, it is going to be difficult...Fear of consequences. (Youth \#8)

I think it's ignorance, like, What? We can't have these issues. You have these issues...We are the perfect culture and you're white, or you're not South Asian, so you guys have the issues. You guys are the ones that do the drugs...NO there are more South Asian kids who are into drugs than other people. So I think it's ignorance, arrogance, and a lack of knowledge, a lack of enthusiasm to seek knowledge or to understand their environment [from South Asian parents and the older generation]. (Youth \#3)

\section{Mental health service knowledge}

When asked to rate their level of knowledge of mental health services and resources on a scale of $1-5$, on average youth felt they did not feel confident in their knowledge. The youth were shown a series of information sheets on 13 local resources for the general public (Centre for Addiction and Mental Health, Canadian Mental Health Association of Peel, Tangerine Walk-in Counselling), youth (Good2Talk helpline, Kids Help Phone, Peel Children's Centre, Nexus Youth Services, Rapport Youth Services, InUrHead website) and ethnospecific services (India Rainbow, Punjabi Community Health Services (PCHS), 315 NISA Muslim Women's Helpline, Naseeha Muslim Youth Helpline). These resources were chosen based on the recommendations of the 33 service providers and professionals interviewed for the study. The youth were asked if they were familiar with the service or had 


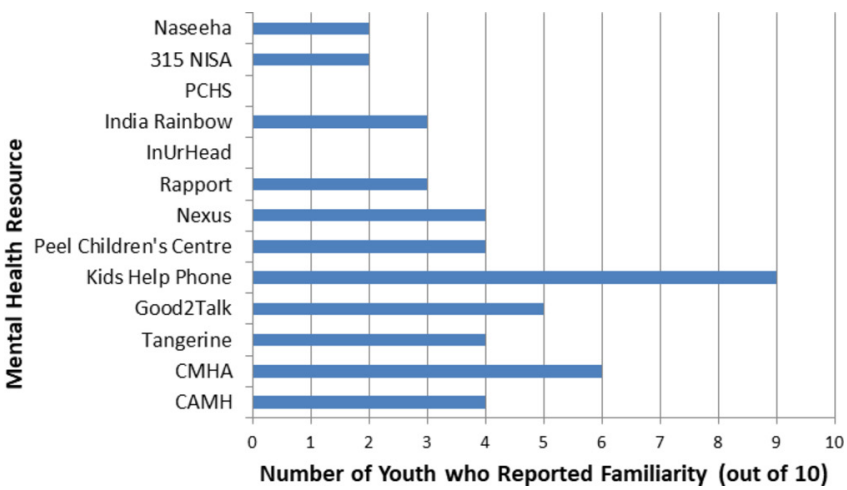

Figure 1 Mental health resource knowledge. This graph portrays the number of participants who reported familiarity with the 22 mental health resources presented to them. CAMH, Centre for Addiction and Mental Health; CMHA, Canadian Mental Health Association of Peel; PCHS, Punjabi Community Health Services.

ever come across any ads or logos. On average, youth were familiar with roughly a third $(36 \%)$ of the mental health services or resources presented to them (figure 1). Considering that many of the youth in the sample were service users themselves, this lack of familiarity with mental health resources is alarming and suggests that youth who may be struggling with mental health issues but not actively seeking mental health services have even lower levels of mental health resource knowledge.

Nine out of ten youth were familiar with Kids Help Phone, while none had seen or heard of PCHS or InUrHead. The majority were familiar with Kids Help Phone because of their extensive ad campaigns within schools, public spaces and on commercial goods (eg, juice boxes). The youth were able to recall some mental health resources through television ads. Service users felt that services that took an open, non-judgemental approach were the best. They particularly appreciated programmes where youth could interact, for example play pool together and have the chance to organically, over time, develop enough trust to share their experiences. They also appreciated programmes where youth were taken on field trips like camping, where they could bond with their peers and youth workers.

\section{Recommendations}

Youth voiced their recommendations for improved mental health services for youth in their community, directed to the school, university, mental health system and South Asian community. South Asian youth felt that mental health awareness and education need to be incorporated into the Ontario curriculum beginning from elementary school. "More the curriculum in school the earlier on...whereas things such as healthy relationships that affect mental health more than physical health... There is hardly ever anything though from a young age" (Youth \#10). In addition, it was recommended that guidance counsellors in schools take on a more proactive role when it comes to mental health, rather than only helping students with academic matters. This will go a long way in normalising help-seeking for mental health issues from a young age. None of the youth had seen a South Asian guidance counsellor at their school and felt increasing the number of staff from racialised backgrounds (teachers and guidance counsellors) would also help break down barriers.

Most of the teachers are Caucasian. They are not as diverse as the students. Yeah, why don't they hire South Asians or Asians? You really don't see, or even African, or black community, I don't see any of them. No. Not seeing any change...Guidance counsellors are mainly used for academics, even though they are there for emotional guidance. (Youth \#6)

Youth felt the university did a better job at promoting mental health than grade school; however, they still felt more could be done. Mental health counselling services on campus, while very convenient, did not address the demands of the youth adequately. Availability of professionals, number of appointments allowed in a given semester and the variety of specialised services offered need to be increased. "Just more people on hand to work with students and also dealing with lots of different therapies" (Youth \#1). Counsellors should also be offered training so they can deal effectively with the mental health needs of South Asian youth. "They should be given special training. Like counselors too. Special training to give resources for the minority groups. Like LGBTQ a hotline. A Sikh student hotline" (Youth \#1).

At the mental health system level, youth recommended increasing free or low-cost services with professionals specifically trained to deal with youth issues, offering services in convenient community locations (shopping plaza, community centre, place of worship and others), increasing the number of South Asian mental health professionals and increasing representation of South Asian youth in mental health promotion material. "I love for there to have posters with a hijabi girl and other South Asian people regarding mental health, you know they are like, you are feeling...those posters, go see a doctor. If you are having these symptoms. Obviously, just generally, South Asian representation needs to increase" (Youth \#1). Youth also wanted to see youth mental health programmes offered that did not necessarily use the term "mental health," for example sports, science or arts-based programmes that fostered social connections and built resilience. Many felt that their parents would be less reluctant to send their kids to extracurricular activities that were not obviously related to mental health. Lastly, youth felt that South Asian beliefs needed to be respected and incorporated within models of mental healthcare.

Youth had a number of recommendations for how parents could promote better intergenerational relationships and understanding in postmigration contexts to deal with acculturation pressures. The majority of youth felt that South Asian parents did little to foster the 
emotional health or build the resilience of their children, although it was viewed as the parents' responsibility to teach their children about mental health. "It's the mother and father's responsibility to teach their kids about it, teach their kids about mental health. Teach them all the things, it is their responsibility to do" (Youth \#8). Youth felt that many of the parenting techniques, such as constantly comparing their kids with other children and extreme academic pressure, were in fact debilitating to their mental health. (When asked if parents fostered emotional health) "Noooo, not even close! Otherwise it was the opposite...They just told it to me in my face. Yeah you're a failure, you're this you're that. Look at this kid, look at that kid. She's done this, she does that" (Youth \#9).

[Parents] always just say, they only say, you have to be big. You have to have good job, you have to have this... They always push you to higher level but they never think that the child cannot take it...But they never, I see white people say to their child, you did a good job, you got an A+. In our South Asian culture, if you get a B+, they will say, why didn't you get an A+? Why didn't you focus? It doesn't help. You need to be appreciative of how much your child is trying. Not all kids are the same. (Youth \#8)

In addition, youth felt their parents' ignorance and denial of mental health issues also presented a major stumbling block. Participants spoke about how their parents did not express their emotions in a healthy or clear manner (particularly fathers) and viewed helpseeking with disdain. "I feel like my dad, is just like, the way, traditional thinking of Pakistani men. Right? Unfortunately. Like it has nothing to do with oh, I will miss you or anything. [i.e. he does not express how much he loves his children.]" (Youth \#1). If parents could be role models and proactive in caring for their own mental health, in addition to the mental health of their children, it would help youth seek care earlier. As outlined earlier, a number of the youth had mothers who had not sought help for their depression. 'You don't talk about emotions, you don't deal with mental health, it doesn't exist. You just need to get a job, go to school, do what you need to do, pay your bills, buy your house. All of that. You just ignore mental health" (Youth \#10).

Youth also felt their parents' obsession with social standing and community repercussions needed to change, especially when it became detrimental to the health of the child. "We need to teach parents that don't look at what other people think. You know? Don't think about what Sharma's family is going to think about it or this family is going to think about it. Do things for your kids" (Youth \#8).

Youth recommended that prominent leaders within the South Asian community like religious leaders, politicians, celebrities and others take a more active role in facilitating mental health awareness and combating mental health stigma within the parental generation.

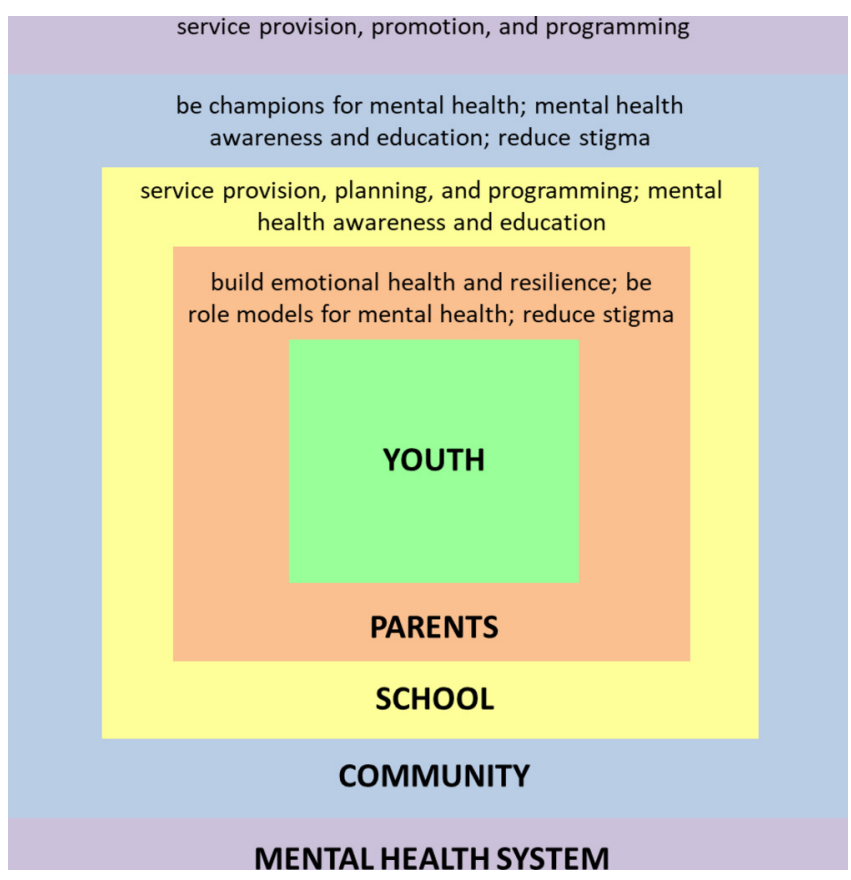

Figure 2 Thematic map of recommendations from youth. The youth discussed the different roles their parents, schools, community and mental health system had to play in order to ensure South Asian youth mental health.

Honestly, because I know a lot of our South Asian [people]...only listen to elders and religious aspects in their life. Try to get them on board and have this information be shared. Pushing this information more...Whenever they are doing whatever celebration or regular attendances to prayers and stuff like do it, try to find a way to fit it in there... They will only listen to the pandit [Hindu religious leader] and no one else. (Youth \#10)

\section{Thematic map}

Participants envisioned a multilevel society working together to ensure South Asian youth mental health and had recommendations for parents, the education system, South Asian community and mental health system (figure 2). Participants recommended that parents take on a foundational role in building the emotional health and resilience of their children. If parents could model positive mental health and encourage help-seeking, this would help to normalise the process and reduce stigma. Youth also envisioned the education system taking on a fundamental role, particularly in teaching children from an early age about mental health. Participants also felt that the school and university both had responsibilities in terms of mental health service provision and had specific recommendations on how they could improve in that respect. Youth felt that prominent leaders within the South Asian community had an important responsibility to champion positive mental health and help to reduce stigma in the parental generation. Places of worship and cultural centres were also well situated to provide mental health awareness and education. Lastly, youth expressed 
their recommendations on how the mental health system in Peel Region could better serve the needs of South Asian youth in terms of mental health services and resources offered, mental health promotion and programming.

\section{DISCUSSION}

This qualitative study provides youth perspectives to understand the mental health challenges and service access barriers experienced by South Asian youth living in Peel Region. The in-depth interviews gleaned rich information and allowed youth participants to speak candidly about the issues they were facing. The interviews point to the multiplicity of perspectives and stress the importance of considering the heterogeneity of youth populations.

Conflicts with parents continually emerged as a major mental health stressor for South Asian youth, with migration and resettlement as the underlying cause of the intergenerational and culture clash between parents and youth. Conflicts regarding career path, dating and relationships, and the young person's desire to adopt 'Western' or 'Canadian' practices have been documented as major sources of conflict within South Asian families. ${ }^{20}{ }^{21}$ Youth usually acculturate faster than their parents, which can cause conflict in terms of language, communication, and the transmission of culture and identity. ${ }^{722}$ Finding themselves in a new country and unable to effectively cope with the rapid fire change, parents often interpret any behaviour that veers from their expectations as a type of cultural/religious betrayal or rebellion, and their typical knee-jerk response is to renew efforts to force their children to conform. ${ }^{23}{ }^{24}$ The youth in this study were aware of the push-and-pull within this struggle, but felt that the power dynamics usually played in favour of the parents. More open dialogue, perhaps with role-playing, where both youth and parents can effectively express their positions, would greatly help in mitigating these conflicts. The Public Health Agency of Canada ${ }^{25}$ promotes the 'Nobody's Perfect' parenting programme for parents with children up to the age of 5 particularly in newcomer neighbourhoods. A similarly tailored, government-sponsored, proven programme to promote more effective communication between newcomer parents and adolescents is needed. Much of this work is happening within the community but funding always remains an issue. There is potential for government and public health agencies to partner with community, religious and cultural institutions to deliver such programmes. Many of the youth participants expressed how ill-equipped their parents are for life in Canada and parenting in a new cultural context. If parents could be armed with the tools needed to effectively foster their children's emotional health, it could go a long way in safeguarding youth mental health.

The connection between first-generation immigrant mothers, PPD and how that impacted on their children's mental health was very interesting. Immigrant women in Canada have a twofold risk of developing PPD and often contend with exacerbating factors such as the stressors of migration and resettlement, low socioeconomic status, lack of social support, and the difficulties of parenting in a new country. ${ }^{26-30}$ In addition, conceptions of PPD may differ for South Asian newcomer mothers in Canada. ${ }^{31}$ It is estimated that about 1100 immigrant women in Peel Region experience PPD every year and face significant barriers to mental health service access. ${ }^{32}$ The youth in this study spoke about the far-reaching impact of their mothers' untreated depression. The depression often made it difficult for mothers to parent effectively, and this in turn affected the youth's mental health. PPD can impact parent-child attachment, cognitive and behavioural development, ${ }^{33}$ and adolescents of depressed parents are at a higher risk for developing the affective or mood disorders themselves. ${ }^{34} 35$ This area warrants further research, and the development of culturally safe PPD and prenatal/ postnatal programmes specifically geared towards immigrant South Asian mothers is needed to ensure South Asian youth mental health. Intergenerational mental health interventions may be particularly helpful in this regard. For example, the 8-week parenting programme SITICAF (Strengthening of Intergenerational/Intercultural Ties in Immigrant Chinese American Families) has been found to be successful in fostering a greater sense of parenting control and increasing the child's self-esteem. ${ }^{36}$

The youth called for culturally safe models of mental healthcare that respected South Asian beliefs and practices. This recommendation is in line with the Mental Health Commission of Canada's Mental Health Strategy. ${ }^{12} 37$ The Journey to Promote Mental Health cultural sensitivity training programme ${ }^{12}$ could be adapted to South Asian populations and offered in areas of high demographic concentration like Peel Region. South Asian youth also felt that beyond 'cultural sensitivity training' capacity needs to be built in order to increase the number of South Asian and other racialised mental health professionals. In addition, the Commission's Multicultural Mental Health Resource Centre ${ }^{12}$ needs to move beyond simple translation of mental health information to cultural adaptation of resource information and increased representation of racialised people within mental health promotion material.

\section{Limitations}

This study's sample size was biased towards mental health service users since many of the referrals came from social workers. Even after months of recruitment, the researchers found it difficult to recruit South Asian youth participants, most likely because of the stigma surrounding mental health and illness. The difficulty with recruitment, the heterogeneity of the participants and the lack of follow-up interviews did not allow for thematic saturation to be achieved. The average level of knowledge of mental health resources for this sample is likely much higher than the general youth population as a result. The bias towards service users made female recruitment for the study more likely. ${ }^{38}$ A South Asian male interviewer was specifically included on the interview team in 
anticipation of this issue but did not prove to be effective in attracting male youth to participate. The social workers tried to encourage their male clients to participate but found that young men were not interested in sharing their views. This may be due to the different socialisation of male and female youth, where men are taught from a young age not to be as open and expressive about their emotions. ${ }^{39}$ Different methods of research enquiry need to be explored that can more effectively engage male youth. However, both male and female participants offered the views of their male peers, for example, many female participants shared the opinions of their male friends and brothers, which contributed to a much more robust male perspective in this study.

\section{CONCLUSIONS}

Peel Region is uniquely situated with a high South Asian concentration. South Asian youth mental health needs to be prioritised and real work needs to begin to bridge gaps in understanding and create partnerships between mainstream mental health services and cultural, religious and community centres that are already taking part in destigmatising efforts and service provision. South Asian youth in Peel Region engaged in thoughtful, candid dialogue. Their perspectives on the mental health stressors and the service access barriers they face have important implications and need to be considered for mental health service delivery and programme planning in Peel Region. Programmes specifically designed to help South Asian youth deal with intergenerational conflict, migration stress, academic pressure, relationship stress, financial worries and family difficulties are needed. Recommendations for increasing the number of South Asian mental health professionals and service capacity need to be considered, among others. Mental health information and promotion need to change to effectively engage South Asian populations. The education system also has a role to play with starting mental health education earlier and having guidance counsellors take a more proactive mental health promotion role. South Asian youth felt that at the university level, the services offered simply did not keep up with the demand of the service needs of students. Lastly, the South Asian community and parents also have a crucial role to play. South Asian youth called for community leaders to take on the role of mental health champions, responsible for spreading awareness about mental health issues within the community and destigmatising help-seeking. Parents have a foundational role to play in building the emotional health and fostering the resilience of their children. Government and community parenting programmes could help in this regard. Taken together, considering the recommendations put forth could go a long way in ensuring the mental health of South Asian youth populations living in Peel Region.
Acknowledgements Special thanks to Amaninder Kaur and Bassaam Salim for conducting interviews and translating research material. Thank you to the Canadian Mental Health Association (CMHA) Peel for partnering on this project.

Contributors FI: conception and design, analysis and interpretation of data, critical writing, and revision of the article. AM: writing of the abstract section of the article. MH, YS, KM: critical review and mentorship of study process, and final approval of the article.

Funding This research was supported by a strategic training grant from the Canadian Institutes of Health Research - Strategic Training Initiative in Health Research (CIHR-STIHR) provided for the Social Aetiology of Mental IIIness (SAMI) Training Program at the Centre for Addiction and Mental Health (CAMH) and the University of Toronto.

Competing interests None declared.

Ethics approval Research ethics were submitted and approved by the Centre for Addiction and Mental Health's Research Ethics Board.

Provenance and peer review Not commissioned; externally peer reviewed.

Data sharing statement If researchers are interested in obtaining samples of recruitment posters, translated consent forms and the interview guide used for this study, please email the corresponding author.

Open Access This is an Open Access article distributed in accordance with the Creative Commons Attribution Non Commercial (CC BY-NC 4.0) license, which permits others to distribute, remix, adapt, build upon this work non-commercially, and license their derivative works on different terms, provided the original work is properly cited and the use is non-commercial. See: http://creativecommons.org/ licenses/by-nc/4.0/

(C) Article author(s) (or their employer(s) unless otherwise stated in the text of the article) 2017. All rights reserved. No commercial use is permitted unless otherwise expressly granted.

\section{REFERENCES}

1. Statistics Canada. (2014). Immigration and ethnocultural diversity in Canada (Catalogue no: 99-010-X). http://www12.statcan.gc.ca/nhsenm/2011/as-sa/99-010-x/99-010-x2011001-eng.cfm

2. Islam T, Selvaratnam I, Shan N. Building an effective South Asian health strategy in Ontario: report for council of agencies serving South Asians. Toronto, Ontario, 2013.

3. McGorry PD, Purcell R, Goldstone S, et al. Age of onset and timing of treatment for mental and substance use disorders: implications for preventive intervention strategies and models of care. Curr Opin Psychiatry 2011;24:301-6.

4. National Institute of Mental Health. (2001). Blueprint for change: research on child and adolescent mental health. https://www.nimh. nih.gov/about/advisory-boards-and-groups/namhc/reports/blueprintfor-change-research-on-child-and-adolescent-mental-health.shtml

5. World Health Organization. Prevention of mental disorders: effective interventions and policy options. Geneva: World Health Organization, 2004. http://www.who.int/mental_health/evidence/en/prevention_of_ mental_disorders_sr.pdf.

6. Weber TR. The influence of acculturation on attitudes toward alcohol and alcohol use within the Punjabi community: an exploratory analysis. Subst Use Misuse 1996;31:1715-32.

7. Anisef P, Kilbride KM. The needs of newcomer youth and emerging 'Best Practices' to meet those needs. Toronto: Joint Centre of Excellence for Research on Immigration and Settlement, 2000.

8. Stuart JE. Pathways to positive development for muslim immigration youth in western contexts (Doctoral dissertation). 2012. http:// researcharchive.vuw.ac.nz/handle/10063/2036

9. Gill IK. Punjabi sikh parents' beliefs about suicide and suicide-related behaviours (thesis). Vancouver, ON: Canada: University of British Columbia, 2010.

10. Tiwari SK, Wang J. Ethnic differences in mental health service use among White, Chinese, South Asian and South East Asian populations living in Canada. Soc Psychiatry Psychiatr Epidemiol 2008;43:866-71.

11. Gadalla TM. Ethnicity and seeking treatment for depression: a Canadian national study. Can Ethn Stud 2010;41:233-45.

12. Calgary AB. Mental Health Commission of Canada. Changing directions, changing lives: the mental health strategy for Canada: Mental Health Commission of Canada, 2012. https://www. mentalhealthcommission.ca/English/system/files/private/MHStrat egy_Strateg y_ENG_0.pdf 
13. Mikkonen J, Raphael D. Social determinants of health: The Canadian facts. Toronto: York University School of Health Policy and Management, 2010.

14. Khanlou N. Mental health promotion education in multicultural settings. Nurse Educ Today 2003;23:96-103.

15. Creswell JW, Plano Clark VL. Designing and conducting mixed methods research. 2nd ed. Thousand Oaks, CA: Sage, 2011.

16. Guba EG, Lincoln YS. Effective evaluation: Improving the usefulness of evaluation results through responsive and naturalistic approaches. San Francisco, CA: Jossey-Bass. 1981.

17. Guba EG, Lincoln YS. Epistemological and methodological bases of naturalistic inquiry. Educational Communication and Technology Journal 1982:30:233-52.

18. Lincoln YS, Guba EG. Naturalistic inquiry. Beverly Hills, CA: Sage, 1985.

19. Braun V, Clarke V. Using thematic analysis in psychology. Qual Res Psychol 2006;3:77-101.

20. Almeida R. Hindu, Christian, and Muslim families. In: McGoldrick M, Giordano J, Pearce JK, eds. Ethnicity and family therapy. New York: Guilford, 1996:395-426.

21. Segal UA. Cultural variables in Asian Indian families. Families in Society 1991;11:233-41.

22. Bernhard JK, Lefebvre ML, Chud G, et al. Linguistic Match between Children and Caregivers in Canadian Early Childhood Education". Canadian Journal of Research in Early Childhood Education, 1996:5:202-22.

23. Sharma AR. Psychotherapy with Hindus. In: Richards RS, Bergin AE, eds. Handbook of psychotherapy and religious diversity. Washington, DC: American Psychological Association, 2000:341-64.

24. Wakil SP, Siddique CM, Wakil FA. Between two cultures: a study in socialization of children of immigrants. J Marriage Fam 1981;43:929-40.

25. Public Health Agency of Canada. Nobody's perfect. 2015. http:// www.phac-aspc.gc.ca/hp-ps/dca-dea/parent/nobody-personne/ index-eng.php

26. Kingston D, Heaman M, Chalmers B, et al. Maternity experiences study group of the Canadian perinatal surveillance system, public health agency of Canada. Comparison of maternity experiences of Canadian-born and recent and non-recent immigrant women: findings from the Canadian maternity experiences survey. J Obstet Gynaecol Can 2011;33:1105-15.
27. Lanes A, Kuk JL, Tamim H. Prevalence and characteristics of postpartum depression symptomatology among Canadian women: a cross-sectional study. BMC Public Health 2011;11:302.

28. Mechakra-Tahiri S, Zunzunegui MV, Seguin L. Self-rated health and postnatal depressive symptoms among immigrant mothers in Québec. Women Health 2007;45:1-17.

29. Myers ER, Aubuchon-Endsley N, Bastion LA, et al. Efficacy and safety of screening for postpartum depression: Agency for Healthcare Research and Quality, 2013.

30. Urquia ML, O'Campo PJ, Heaman MI. Revisiting the immigrant paradox in reproductive health: the roles of duration of residence and ethnicity. Soc Sci Med 2012;74:1610-21.

31. Meiyappan S, Lohfeld L. The First Time Mothering Experiences of Sri Lankan Tamils. Demeter Press; 2013. Toronto: New Mothers in a New Land, 2013

32. Bodolai $P$, Celmins $M$, Viloria-Tan $E$. Use of services by immigrant women with symptoms of postpartum depression. region of peel. 2014. http://www.peelregion.ca/health/library/pdf/serv-immigrantwomen-postpart- depression.pdf

33. Paediatrics \& Child Health. Maternal depression and child development. Paediatr Child Health 2004:9:575-83.

34. Klein DN, Depue RA, Slater JF. Cyclothymia in the adolescent offspring of parents with bipolar affective disorder. J Abnorm Psychol 1985;94:115-27.

35. Lewinsohn PM, Hops H, Roberts RE, et al. Adolescent psychopathology: I. Prevalence and incidence of depression and other DSM-III-R disorders in high school students. J Abnorm Psychol 1993;102:133-44.

36. Ying $Y-W$. Strengthening intergenerational/intercultural ties in migrant families: A new intervention for parents. J Community Psychol 1999;27:89-96.

37. Mental Health Commission of Canada. The Mental Health Strategy for Canada: A Youth Perspective. Mental Health Commission of Canada's Youth Council. 2015. http://www.mentalhealthcommission. ca/English/system/files/private/document/2015-03-1617-MHCCYouthStrategyReport-E-FINAL.pdf

38. World Health Organization. Gender and women's mental health 2017. http://www.who.int/mental_health/prevention/genderwomen/ en/

39. Lewis RA. "Emotional Intimacy among Men" In book: the gender gap in psychotherapy, 1978:181-93. http://link.springer.com/chapter/. 